\title{
Relationship between Chinese and International Crude Oil Prices: A VEC-TARCH Approach
}

\author{
Changming Song and Chongguang $L i$ \\ College of Economics \& Management, Huazhong Agricultural University, Wuhan 430070, China \\ Correspondence should be addressed to Chongguang Li; lcg@mail.hzau.edu.cn
}

Received 29 April 2015; Revised 27 September 2015; Accepted 8 November 2015

Academic Editor: Reik Donner

Copyright (C) 2015 C. Song and C. Li. This is an open access article distributed under the Creative Commons Attribution License, which permits unrestricted use, distribution, and reproduction in any medium, provided the original work is properly cited.

\begin{abstract}
Many studies focus on the impact of international crude oil price volatility on various economic variables in China with a hypothesis that international crude oil price affected Chinese crude oil price first and then other economic variables. However, there has been little research to explore whether or not international and Chinese oil market are integrated. This study aims to investigate the relationship between Chinese and international crude oil prices by VAR and VEC-TARCH models. It was found that the two crude oil markets have been integrated gradually. But the impact of external shocks on the Chinese crude oil market was stronger and the Chinese crude oil price was sensitive to changes in international crude oil price, implying that the centrally controlled oil market in China is less capable of coping with external risk. In addition, the volatility of both Chinese and international crude oil prices was mainly transmitted by prior fluctuation forecast and the impact of external shocks was limited, demonstrating that in both cases volatility would disappear rather slowly. Furthermore, Chinese and international crude oil markets have established a stable relationship. When the direction of external shocks on the two variables' respective stochastic term was consistent, the impact on the two variables' joint volatility was aggravated and vice versa.
\end{abstract}

\section{Introduction}

There is an extensive body of literature analyzing the impact of oil price fluctuations on the Chinese economy [1]. Positive oil price shocks had negative effects on Chinese macroeconomics [2]. The global oil price affected both China's economic growth and inflation whereas China's economic activity failed to affect the world oil price [3]. Besides, oil price increase negatively affected output and investment [4]. China's imports and exports, which are important for the Chinese economy, are also correlated with the oil price $[5,6]$.

The impact level of oil price shocks on Chinese industries may be different. Negative oil price shocks had strong influences on Chinese grains, metals, petrochemicals, and oil fats [7]. On the other hand, a positive oil price shock leads to significant profit increases for the Chinese petroleum and natural gas extraction industry but negative influence on petroleum processing industry [8]. Moreover, the oil price volatility depresses the oil company index and may increase the speculations in the mining index and petrochemicals index in China [9]. In contrast to metals and grains, petrochemicals and oil fats indices responded to global oil price shocks [10].

Oil price shocks can affect stock returns in China [1113], and the correlations between oil price shocks and stock returns are systematically time-varying [14]. There is a cointegration relationship between oil prices and Chinese stock prices at the disaggregated sector level and there are some structural breaks in the interaction between them [15]. Higher oil prices may cause lower stock prices whereas positive shocks to oil market-specific demand resulted in higher stock price [16]. In addition, the impact of international oil prices on emerging economies' stock markets is different [17]. China's stock returns are correlated only with the expected volatility in world oil prices [18].

Parts of the literature pay attention to the relationship between oil prices and various price indices. Oil price shocks lead to a contemporaneous increase in consumer and producer price indices [19]. However, the impact of the WTI (West Texas Intermediate) crude oil price shocks on import 
price index, producer price index, and retail price index weakens gradually [20].

On the other hand, the increasing oil demand in China may exert an impact on the international crude oil price [2124]. The world oil price rise could partly contribute to Chinese oil demand [25]. The demand from emerging markets such as China has become a significant factor in the world oil pricing system [26]. The cumulative impact of real G3 (USA, Eurozone, and Japan) real M2 (broad money) shocks on real oil prices is small while the impact of China's real M2 on the real price of crude oil is large and statistically significant [27]. However, China's crude oil imports do not significantly affect Brent price changes and there is no solid evidence to illustrate that dramatic fluctuations of international oil price have effect on China's crude oil imports [28].

Why and how did international oil price influence the Chinese economy and various macroeconomic variables? Obviously, the most sensitive economic indicator to international oil price change should be the domestic crude oil price. If the Chinese crude oil market was integrated with the international crude oil market, other macroeconomic variables in China would be impacted by the international crude oil price through the domestic crude oil price. In turn, if it were isolated, it would be impossible to set up a linkage between international crude oil price and domestic macroeconomic indicators. That is, international oil price shocks usually transmit to the Chinese domestic oil price first and then impact other macroeconomic indicators subsequently. Thus, it is important to explore the relationship between Chinese and international crude oil prices.

The contribution of this paper is that we can compare the commodity price fluctuation risk between market-oriented and partially regulated economies in the perspective of crude oil markets. As we know, the oil markets in Western countries such as the USA or Great Britain are highly marketoriented while the Chinese are chiefly controlled by the central government, specifically the National Development and Reform Commission. Since 1998, the Chinese government has made attempts to reform its crude oil pricing mechanism $[29,30]$, which was demonstrated in the Chinese crude oil and refined oil price reform plan released by the National Development and Reform Commission on June 3, 1998. The final goal of the oil price reform was to gradually integrate its crude oil market with the international market. However, the crude oil industry, especially the upper-stream oil industry, is still controlled by a few oligopolies. Besides, unlike other highly market-oriented commodities, crude oil pricing rights belong to the central government. The crude oil market in China is full of bureaucratic control. On the other hand, whether initiatively or passively, the Chinese crude oil market has become gradually connected with the world oil market. Notably, crude oil is an important industrial raw material and the volatility of its price will influence economic growth. As the Chinese economy develops rapidly, the demand for crude oil in the country has increased rapidly as well. A remarkable fact is that China's domestic crude oil's external dependence increases gradually. As the China Statistical Yearbook showed, the crude oil import in 2014 was roughly 310 million tons, increasing by $9.4 \%$ from the previous year. China's crude oil's external dependence rate has grown gradually in recent years; in 2007, 2008, 2009, 2010, $2011,2012,2013$, and 2014, the external dependence rates were $47.2 \%, 49.8 \%, 52 \%, 54.8 \%, 56.5 \%, 56.8 \%, 57.3 \%$, and $59.5 \%$, respectively. Compared to the highly market-oriented oil market, whether the government-controlled crude oil market is more capable of resisting the market risk is a meaningful issue, and the features of the Chinese crude oil market give us an appropriate chance to explore the problem.

The remainder of this paper is organized as follows. Section 2 briefly reviews the evolvement of the Chinese crude oil price. Section 3 introduces the methodology and the data. Section 4 presents the results for the Chinese and international crude oil market.

\section{Evolution of the Chinese Crude Oil Price Mechanism}

During the era of planned economy in China, namely, before 1978, the government set almost every commodity's price, including crude oil price. As a result, China's crude oil market was completely isolated from the international crude oil market. After 1981, keeping pace with the central government's reform of the planned economic system, two pricing systems appeared concerning the crude oil price, which was known as the double pricing system (DPS). One kind of prices was determined by the central government while the other was spontaneously adjusted by the demand and supply of crude oil. However, the centrally controlled price still dominated the market until 1993 when Chinese crude oil was self-sufficient. As a result, during this period, the Chinese crude oil price was still isolated from the international crude oil market. After 1993, with the rapid economic development in China, the demand for crude oil increased greatly and domestic crude oil supply could not fulfill this demand. From this time, China has changed from a crude oil exporting country to a net importer in the international crude oil market. Consequently, China's economic development was gradually affected by the volatility of the international crude oil price. By 1998, the Chinese government explicitly declared the reform of the crude oil pricing mechanism aiming to integrate its oil market with the international market. The domestic crude oil settlement price in China was then composed of a benchmark price and premium. The government, based on Singapore FOB price plus freight, insurance, and tariff, determined the former and the buyers and sellers negotiated the latter. The standard retail price in various regions was announced by the central government and the two oil monopoly giants, known as Sinopec and PetroChina, could set up a retail price within a 5\% floating range based on the standard retail price in 1998. This floating range increased to $8 \%$ in 2001 . However, the standard retail price has been mastered by government.

\section{Methodology and Data}

3.1. VAR Model. This study investigates empirically the interrelationship between Chinese and international crude oil prices in the framework of Vector Autoregressive (VAR) 
and Multivariate General Autoregressive Conditional Heteroskedasticity (MGARCH) models, which are both widely used in the economic literature. The VAR model was firstly applied to macroeconomics to explore the interrelationship of economic variables [31]. A basic $q$-lag VAR model including $N$ endogenous variables (in this study $N$ equals 2) was defined as follows:

$$
\begin{aligned}
& p \_1_{t}=c_{1}+\sum_{i=1}^{q} \alpha_{1 i} \cdot p \_1_{t-i}+\sum_{i=1}^{q} \beta_{1 i} \cdot p \_2_{t-i}+\varepsilon_{1 t}, \\
& p 2_{t}=c_{2}+\sum_{i=1}^{q} \alpha_{2 i} \cdot p 2_{t-i}+\sum_{i=1}^{q} \beta_{2 i} \cdot p \_1_{t-i}+\varepsilon_{2 t},
\end{aligned}
$$

where $p_{-} 1$ and $p_{\_} 2$ refer to Chinese and international crude oil prices, respectively, and $q$ is the model order. $\varepsilon_{1 t}$ and $\varepsilon_{2 t}$ refer to the corresponding regression equations' stochastic terms with $E\left(\varepsilon_{n t}\right)=0 . \varepsilon_{1 t}$ and $\varepsilon_{2 t}$ are both white noise series with $E\left(\varepsilon_{n t_{1}} \varepsilon_{n t_{2}}\right)=0\left(t_{1} \neq t_{2}\right)$ and $E\left(\varepsilon_{1 t} \varepsilon_{2 t}\right)=\sigma$.

Before we start to utilize the VAR model to investigate the relationship between the crude oil prices in China and in the world, one of the premises is that they do impact each other; that is to say, both of them should be treated as endogenous variables of each other. The Granger causality model [32], which tests causal relationship between time series variables, could be employed to explore whether they affected each other statistically. Essentially, the Granger causality model is a nonstructured VAR model.

The VAR model is a dynamic and endogenous system, so the impact of external shocks on all variables in the system is dynamic as well. As some of the parameters in the VAR model are usually not statistically significant, the impulse response function and variance decomposition (together called "innovation accounting") are often adopted to further analyze an external shock's dynamic impact. A shock to the $i$ th variable not only directly affects the $i$ th variable but is also transmitted to all other endogenous variables through the dynamic (lag) structure of the VAR model. An impulse response function traces the effect of a one-time shock to one of the innovations on current and future values of the endogenous variables $p_{-} 1$ and $p_{-} 2$. It can be written as $\partial E\left(y_{t+k} \mid \varepsilon_{n t}\right) / \partial \varepsilon_{n t}$, where $k \geq 0$ and $y$ denotes $p_{-} 1$ or $p \_2$. Obviously, an impulse response function reflects the impact of a shock in the $n$th variable on the expected value of $y_{t+k}$ [33].

Variance decomposition can measure the contribution of various structural shocks. The moving average forms of (1) read as follows:

$$
\begin{aligned}
& p \__{t}=\sum_{t=1}^{\infty} \theta_{1}^{(t)} \varepsilon_{1 t}+\sum_{t=1}^{\infty} \theta_{2}^{(t)} \varepsilon_{2 t}, \\
& p 2_{t}=\sum_{t=1}^{\infty} \theta_{2}^{(t)^{\prime}} \varepsilon_{2 t}+\sum_{t=1}^{\infty} \theta_{1}^{(t)^{\prime}} \varepsilon_{1 t} .
\end{aligned}
$$

Assuming that there is no serial correlation between $\varepsilon_{1}$ and $\varepsilon_{2}$ in the same period, the variances of (2) are given by

$$
\begin{aligned}
& \operatorname{var}\left(p \_1_{t}\right)=\sum_{t=1}^{\infty}\left(\theta_{1}^{(t)}\right)^{2} \sigma_{1 t}^{2}+\sum_{t=1}^{\infty}\left(\theta_{2}^{(t)}\right)^{2} \sigma_{2 t}^{2}, \\
& \operatorname{var}\left(p \_2_{t}\right)=\sum_{t=1}^{\infty}\left(\theta_{2}^{(t)^{\prime}}\right)^{2} \sigma_{2 t}^{2}+\sum_{t=1}^{\infty}\left(\theta_{1}^{(t)^{\prime}}\right)^{2} \sigma_{1 t}^{2} .
\end{aligned}
$$

$\sigma_{1 t}^{2}$ and $\sigma_{2 t}^{2}$ are the variances of the stochastic terms in (1). Evidently, the right two terms' respective proportion to the left term in (3) gives the corresponding variance contribution (the same applies to (4)).

3.2. VEC-TARCH Model. When setting up a regression model of time series variables, one of the key assumptions is homoscedasticity of the stochastic error term. However, economic time series usually exhibit the feature of volatility clustering, which means that the variance of the stochastic term is variable. In such case, a MGARCH model may be more suitable. There are various MGARCH models including the VEC [34], CCC [35], BEKK [36], and DCC models [37] to describe the conditional variance-covariance matrix in a MGARCH model. The conditional variance-covariance matrix should satisfy the positive definiteness condition. In addition, the number of parameters to be estimated increases rapidly as the dimension of the variables increases. Fortunately, in the previous study there are only two variables, so we just adopt the common VEC model. Actually, the VEC model is based on the univariate GARCH model [38] and is its direct generalization:

$$
H_{t}=C_{0}+\sum_{i=1}^{p} A_{i} \otimes\left(\varepsilon_{t-i} \varepsilon_{t-i}^{\prime}\right)+\sum_{j=1}^{q} B_{j} \otimes H_{t-j} .
$$

We proceed by formulating a VEC model for the residuals $\varepsilon_{1 t}$ and $\varepsilon_{2 t}$ in (1) for the Chinese and international crude oil prices. The VEC model, shown in (5), is usually used to simulate two variables. In (5), the conditional variancecovariance matrix $H_{t}$ is a linear function of the lagged squared errors and the lagged values of the elements of itself. $C_{0}$ is a constant coefficient matrix whereas $A_{i}$ and $B_{j}$ are coefficient matrices of lagged squared errors and lagged values of $H_{t}$, respectively. Both matrices $A_{i}$ and $B_{j}$ are symmetric so as to reduce the number of estimated parameters [34]. $\otimes$ is Hadamard product operator, representing the corresponding term's multiplication. Since a $\operatorname{GARCH}(1,1)$ model can already describe a vast number of time series variables, the values of both $p$ and $q$ are restricted to one in this study. In addition, when the coefficients of the VEC model were estimated, the matrix $C_{0}$ is limited to being a scalar. In order to reflect the coefficients' economic meanings clearly in the matrices $H_{t}, C_{0}, A_{i}$, and $B_{j}$, (5) is rewritten in the form of a set of equations as follows:

$$
\begin{aligned}
& h_{11 t}=c_{0}+a_{11} \varepsilon_{1(t-1)}^{2}+b_{11} h_{11(t-1)}, \\
& h_{22 t}=c_{0}+a_{22} \varepsilon_{2(t-1)}^{2}+b_{22} h_{22(t-1)}, \\
& h_{12 t}=c_{0}+a_{12} \varepsilon_{1(t-1)} \varepsilon_{2(t-1)}+b_{12} h_{12(t-1)} .
\end{aligned}
$$


The second and third term on the right-hand side in (5), (6), and (7) are referred to as ARCH and GARCH terms, respectively. As both $A_{i}$ and $B_{j}$ are symmetric matrices, $a_{12}=a_{21}$ and $b_{12}=b_{21}$. Moreover, as $C_{0}$ is a scalar, $h_{12 t}=h_{21 t}$. Equations (6) and (7) are the corresponding $\operatorname{GARCH}(1,1)$ models of the Chinese and international crude oil prices. $a_{11}$ and $b_{11}$ measure the impact of external shocks and China's domestic crude oil price's conditional variance in the last period on the current price volatility, while $a_{22}$ and $b_{22}$ measure that of the international crude oil price. Equation (8) is the $\operatorname{GARCH}(1,1)$ model of the conditional covariance for the Chinese and international crude oil prices. $a_{12}$ and $b_{12}$ measure the impact of the joint stochastic term's shocks and the conditional covariance of Chinese and international crude oil prices in last period on the current joint volatility. The squared errors $\varepsilon_{t}^{2}$ follow a heteroskedastic $\operatorname{ARMA}(1,1)$ process. The autoregressive root which governs the persistence of volatility shocks is the sum of $a$ and $b$. In many applications, this root is very close to 1 so that shocks die out rather slowly.

A VEC-TARCH model is formulated by the combination of TARCH and VEC models. The TARCH model serves to explore whether positive and negative news' impacts on current volatility are symmetric or not [39] and reads as follows:

$$
h_{t}=c_{0}+\sum_{i=1}^{q} a_{i} \varepsilon_{t-i}^{2}+\varphi \varepsilon_{t-1}^{2} d_{t-1}+\sum_{j=1}^{p} b_{j} h_{t-j},
$$

where $d_{t-1}$ is a dummy variable. When $\varepsilon_{t-1}<0, d_{t-1}=1$; that is, negative external news influences the current conditional variance as $\sum_{i=1}^{q} a_{i}+\varphi$, whereas when $\varepsilon_{t-1}>0, d_{t-1}=0$; that is, the influence of positive external news in the last period is $\sum_{i=1}^{q} a_{i}$. Obviously, when $\varphi<0$, the impact of positive news is greater than that of negative news and vice versa.

The VEC-TARCH model

$$
\begin{aligned}
H_{t}= & C_{0}+\sum_{i=1}^{p} A_{i} \otimes\left(\varepsilon_{t-i} \varepsilon_{t-i}^{\prime}\right)+\varphi_{1} \otimes\left(\varepsilon_{t-1} \varepsilon_{t-1}^{\prime}\right) \otimes d_{t-1} \\
& +\sum_{j=1}^{q} B_{j} \otimes H_{t-j}
\end{aligned}
$$

adds another term based on (5), which is similar to the second term on the right-hand side of (9). Here, $d_{t-1}$ is a virtual variable matrix. When the corresponding stochastic term or covariance in the last period is negative, $d$ equals one; else it equals zero. The elements of the coefficient matrix $\varphi_{1}$ reflect the asymmetric impact of positive and negative news on the current volatility.

3.3. Data. In this study, the crude oil price in China was represented by the Daqing crude oil spot price, while the international crude oil price was represented by that of West Texas Intermediate (WTI), which is influential to the international crude oil market. The sample period was from January 1991 to October 2011, which includes 250 monthly observations. In terms of oil reserves and annual output, the Daqing oil field is the biggest in China and this is the reason
TABLE 1: Granger causality test between $p_{-} 1$ and $p_{-} 2$. “****, “**," and " $*$ " denote the significance at the $1 \%, 5 \%$, and $10 \%$ level, respectively.

\begin{tabular}{lcc}
\hline Null hypothesis & Lag length & $F$ statistics \\
\hline Chinese $\rightarrow$ International & 1 & $5.3098^{* *}$ \\
International $\rightarrow$ Chinese & 1 & $42.2504^{* * *}$ \\
Chinese $\rightarrow$ International & 2 & $2.7105^{*}$ \\
International $\rightarrow$ Chinese & 2 & $21.3865^{* * *}$ \\
Chinese $\rightarrow$ International & 3 & $7.2521^{* * *}$ \\
International $\rightarrow$ Chinese & 3 & $17.5957^{* * *}$ \\
Chinese $\rightarrow$ International & 4 & $6.0005^{* * *}$ \\
International $\rightarrow$ Chinese & 4 & $14.2767^{* * *}$ \\
Chinese $\rightarrow$ International & 5 & $3.9856^{* * *}$ \\
International $\rightarrow$ Chinese & 5 & $10.3246^{* * *}$ \\
Chinese $\rightarrow$ International & 6 & $3.3720^{* * *}$ \\
International $\rightarrow$ Chinese & 6 & $7.9653^{* * *}$ \\
\hline
\end{tabular}

why the Daqing crude oil spot price was chosen to denote the Chinese crude oil price. All data were collected from the US Energy Information Administration.

\section{Empirical Results and Discussion}

Many time series are nonstationary, implying that their means are nonconstant. In this case, the results of modeling these nonstationary variables may be inaccurate. Therefore, it is necessary to test whether or not time series are stationary before setting up an empirical model. We carried out an augmented Dickey-Fuller (ADF) test with the null hypothesis that the Chinese or international crude oil price has a unit root. Both $\mathrm{ADF}$ tests for the dependent variables $p_{-} 1$ and p_2 include an intercept term and linear trend with zero lag. Least squares are used to compute the coefficients and $t$ statistics of the ADF test equations based on the 248 observations from March 1991 to October 2011. Following Schwarz' information criterion, the results showed that the $t$ statistics of the ADF test equations of $p_{-} 1$ and $p \_2$ were -13.4866 and -10.1360 , respectively, which both are larger than the test's critical values of -3.9955 at $1 \%$ significance level. This implies that we can reject the null hypothesis that the Chinese or international crude oil price has a unit root; that is, $p_{-} 1$ and $p \_2$ were stationary at the significance level of 0.01 .

4.1. Granger Causality Test. Before setting up an empirical model of Chinese and international crude oil prices, we should identify the interrelationship between the two variables, that is, whether one's impact on the other is endogenous or exogenous. The Granger causality test can help to statistically infer a causal relationship between Chinese and international crude oil prices. The result of the Granger causality test is sensitive to the model orders (maximum lags); so we tested the relationship of the two variables when lagged from one to six. As is shown by the $F$ statistics in Table 1, the null hypothesis that "the Chinese crude oil price did not Granger-cause the international crude oil price" was 
TABLE 2: VAR lag order selection criteria. “*” indicates the model order selected by the corresponding criterion. LR, FPE, AIC, SC, and HQ are the sequential modified LR test statistic (each test at $5 \%$ level), final prediction error, Akaike information criterion, Schwarz information criterion, and Hannan-Quinn information criterion, respectively.

\begin{tabular}{lcccccc}
\hline Lag & $\log L$ & LR & FPE & AIC & SC & 11.2996 \\
\hline 0 & -1367.404 & NA & 269.0939 & 11.2708 & 10.9479 & 11.0341 \\
1 & -1324.168 & 85.4046 & 194.8317 & 10.8909 & 11.0347 & 10.9826 \\
2 & -1313.248 & 21.3914 & 184.0463 & 10.7512 & $10.9525^{*}$ & 10.9488 \\
3 & -1292.276 & $40.7359^{*}$ & 160.0553 & $10.7477^{*}$ & 11.0064 & $10.8323^{*}$ \\
4 & -1287.843 & 8.5366 & $159.4924^{*}$ & 10.7542 & 1.0704 & 10.8519 \\
5 & -1284.629 & 6.1377 & 160.5360 & 10.7525 & 11.1262 & 10.9815 \\
6 & -1280.429 & 7.9516 & 160.2842 & & \\
\hline
\end{tabular}

always rejected. At the same time, the null hypothesis that "the international crude oil price was not Granger-cause of the Chinese crude oil price" was rejected as well when lagged from one to six time steps. Taken together, Chinese and international crude oil prices were mutual Granger-causes of each other, illustrating that they did affect each other empirically, which is inconsistent with previous results that China had little impact on the volatility of the international crude oil markets [40].

High external oil dependence in China implies its strong demand for crude oil from the international markets. China has been the second largest oil consuming country since 2003 and in 2008 it became the second largest oil importing country. Roughly $60 \%$ of the total oil consumption in China was imported in 2014. With further development of marketization in China, the domestic crude oil price could reflect its supply and demand situation to some extent, which would transmit to the international crude oil market, thereby affecting the international oil price. Moreover, the benchmark price in the Chinese crude oil market was determined based on the international crude oil price (specifically, the Singapore crude oil price from 1998 to 2001 and the average price of the New York, Rotterdam, and Singapore crude oil futures markets after 2001).

4.2. VAR Model. On the basis of the above analysis, we know that the Chinese and international crude oil prices had constituted a mutual influencing endogenous system. Therefore, an unstructured VAR model is employed to further investigate their dynamic relationship.

The first step to set up the VAR model is to determine the lag order. As is shown in Table 2, the optimal lag was three according to the LR, SC, and HQ criteria while it was four following the FPE and AIC information criteria. The lag four statistics for FPE and AIC only slightly differed from the lag three statistics. As a result, the order of the VAR model was chosen as three.

4.2.1. Impulse Response Function. The economic meaning of the coefficients in the VAR model is not evident and some of them are usually not statistically significant. Furthermore, the VAR model is a dynamic system and an external shock to any endogenous variable will affect all the variables in the model. Therefore, impulse response function and variance decomposition are commonly utilized to investigate the variables' relationship in a VAR model. The impulse response function reflects all the endogenous variables' time-varying response to any variable's external shocks. The dashed line in Figure 1 shows the \pm 2 standard deviation error band, representing the $5 \%$ level of significance. In order to transform the impulse, we choose the Cholesky decomposition method, which utilizes the inverse of the Cholesky factor of the residual covariance matrix to orthogonalize the impulses, imposes an ordering of the variables in the VAR model, and attributes all of the effect of any common component to the variable that comes first in the VAR system.

When the crude oil price in China was affected by an external shock of one unit standard deviation, it would be positively influenced itself for about seven months (Figure 1(a)). The impact on its price from the first to fifth month was positive. In the first month, the price increased drastically by 4.77 dollars while from the second to the fifth month its price rose by $0.79,0.75,0.19$, and 0.37 dollars, respectively. In the sixth and seventh period, Chinese crude oil prices decreased but the magnitude was small. An external shock to the crude oil price in China positively affected the international crude oil price for roughly eight months. The international crude oil price in the second period increased by 1.96 dollars and fluctuated in the following seven periods, but the magnitudes were small as well (Figure 1(b)). Similarly, when the international crude oil price was affected by an external shock of one unit standard deviation, it grew by about 2.55 dollars in the first month and then fluctuated slowly from the second to the seventh month (Figure 1(c)). From the eighth period on, it was restored to the level before the shocks. An external shock to the international crude oil price positively affected the Chinese crude oil price for approximately four months, increasing by about $2.89,1.43$, 1.08 , and 0.99 dollars from the first to the fourth period, respectively (Figure 1(d)). The Chinese crude oil price was sensitive to the international crude oil price shocks and experienced a relatively long increase in response to the rise of the international crude oil price.

In brief, regardless of whether an external shock acted on the Chinese or international crude oil price, the magnitude of the Chinese crude oil price volatility in the first period overweighed that of the international crude oil price, suggesting that the crude oil price in China was more sensitive to external shocks than the international one. A possible explanation is that China's domestic oil market mechanism 


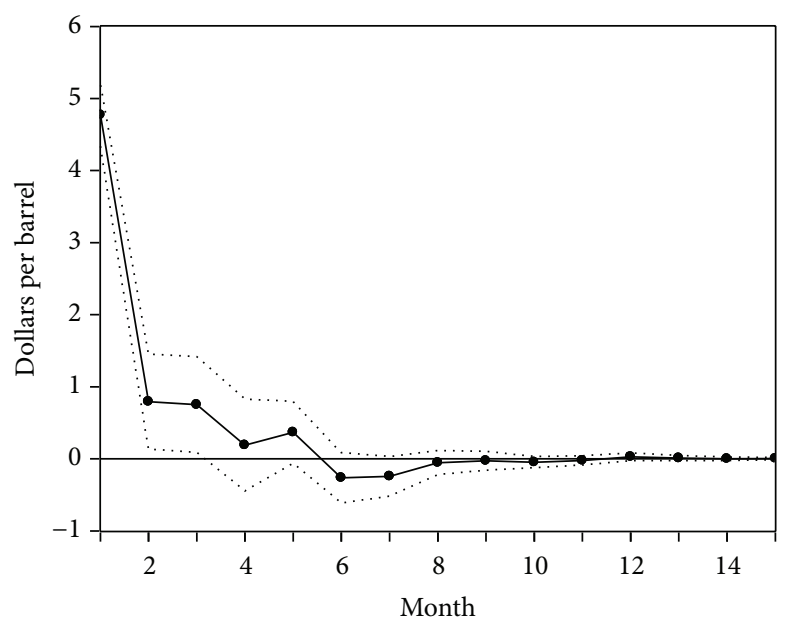

(a)

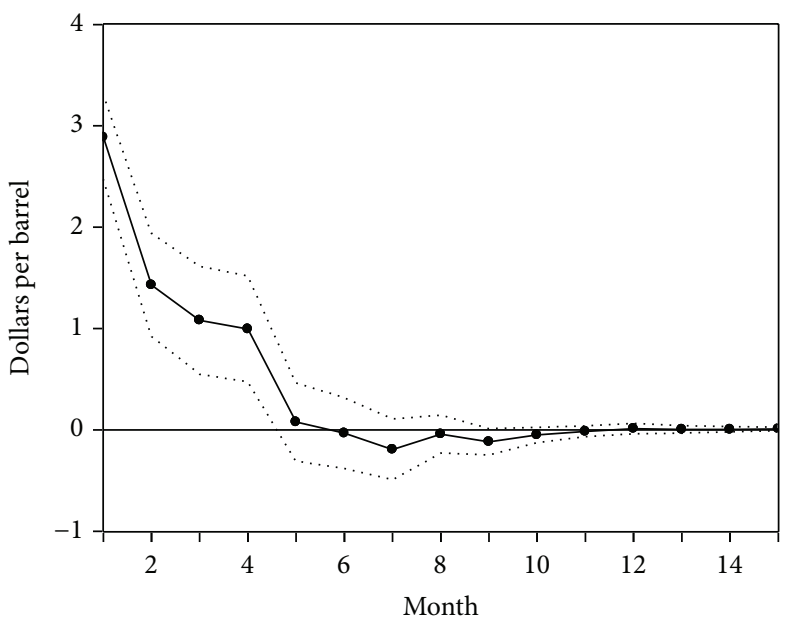

(c)

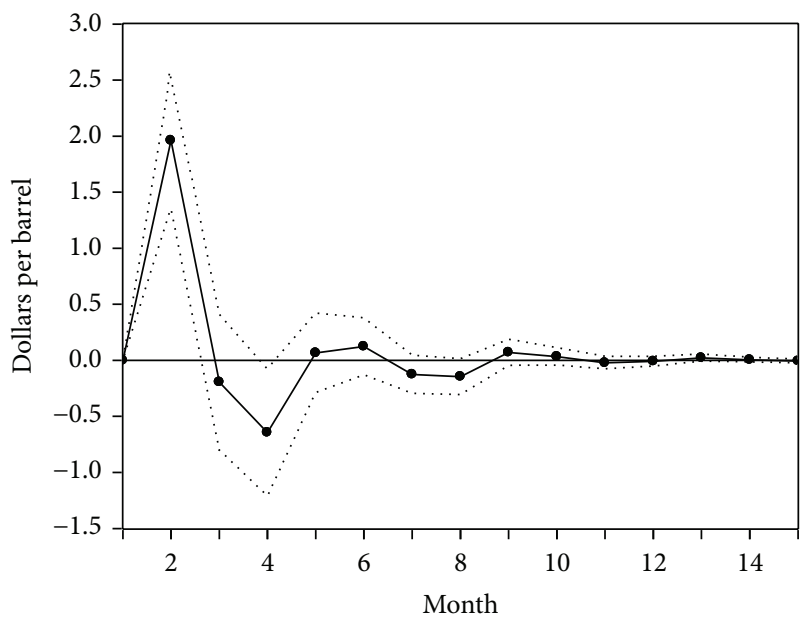

(b)

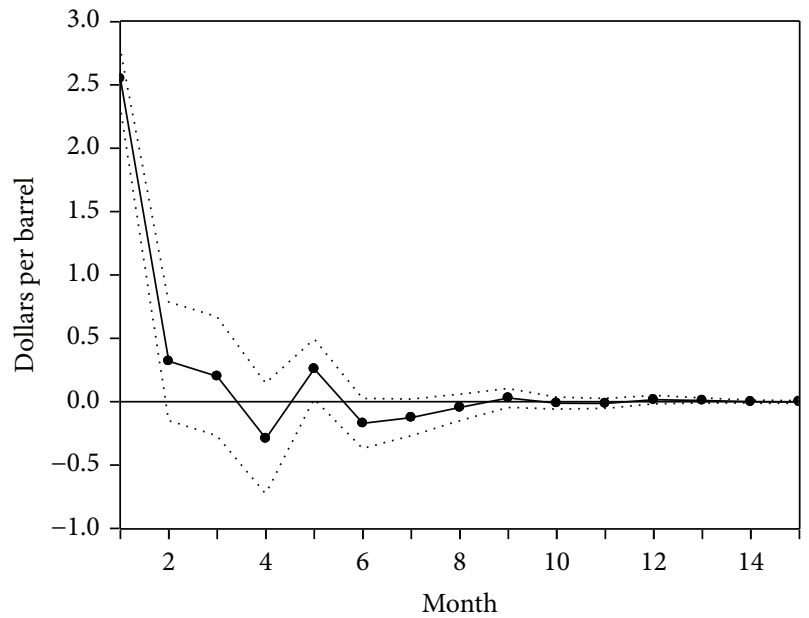

(d)

Figure 1: Response of $(\mathrm{a}, \mathrm{c}) p_{-} 1$ and $(\mathrm{b}, \mathrm{d}) p_{\_} 2$ to shocks of the (a, b) Chinese and (c, d) international crude oil price. Solid (dotted) lines denote the mean innovation ( \pm 2 standard deviations).

needed to be improved further to enhance its buffering capacity to external shocks. Consequently, the partially planned economies' mechanisms in crude oil markets seemed to be more vulnerable to external risk than market-oriented mechanisms. In addition, the reason why the crude oil price in China would experience a relatively long increase after an external shock to the international oil price is that it was determined by the average price of the New York, Rotterdam, and Singapore futures markets of the last month starting from October 2001, which were all closely related to the West Texas Intermediate crude oil price.

4.2.2. Variance Decomposition. Based on the results of the Granger causality test and the impulse response function, we know that the relationship between the Chinese and international crude oil prices was mutual and dynamic. Through the VAR model, current Chinese crude oil price volatility would affect the Chinese and international crude oil prices in the next period, then influencing the third period's prices, and so forth. Variance decomposition can measure the contribution of structural shocks of all the endogenous variables to any analyzed variable in the VAR model. In other words, it is possible to assess the relative significance of different structural shocks.

The results of variance decomposition were estimated by the Cholesky decomposition method and shown in Figure 2. In terms of the international crude oil price, the relative contributions of the Chinese and international crude oil prices were $56.19 \%$ and $43.81 \%$, respectively, in the first period (Figure 2(a)). Then the contribution of the Chinese crude oil price gradually increased to $65.08 \%$ in the fourth period. Since the fifth period, the two variables' respective contribution to structural shocks from the international crude oil price tended to stabilize. In short, the contribution of the Chinese crude oil price to the international crude oil price was stronger. A possible interpretation of this finding is that the internal stabilization mechanism of the Chinese crude oil price was less stable than that of the international crude oil price. No matter the origin of the initial external shock, the results of the impulse response function showed that the 


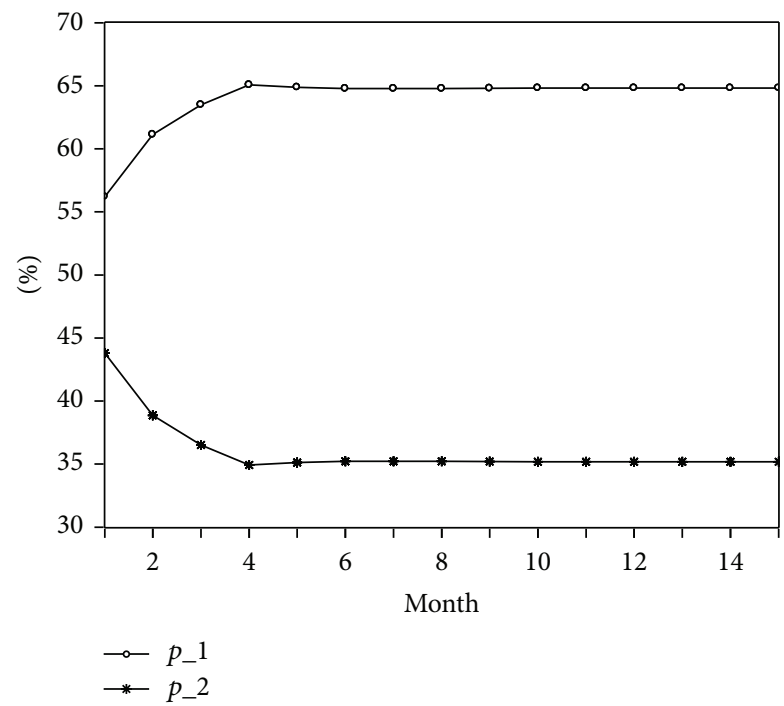

(a)

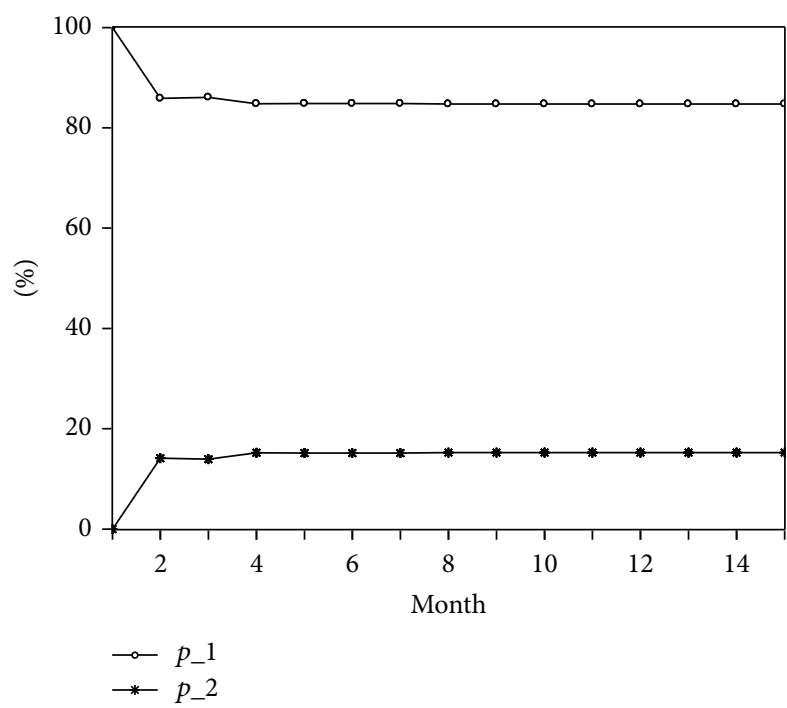

(b)

FIGURE 2: Variance decomposition of (a) $p \_2$ and (b) p_1.

Chinese crude oil price was affected more deeply. In addition, the impact of the Chinese crude oil price volatility on itself was stronger than that of the international crude oil price. As a result, the international crude oil price's relative influence on itself was smaller. When it came to the Chinese crude oil price, as is shown in Figure 2(b), in the second period, the contributions of the Chinese and international crude oil prices were $85.87 \%$ and $14.13 \%$, respectively, and in the third period $86.04 \%$ and $13.96 \%$. From the fourth period on, Chinese crude oil price's impact on itself stabilized at about $85 \%$, whereas that of the international crude oil price was approximately $15 \%$. In summary, the Chinese crude oil price's impact on itself was stronger and that of the international crude oil price was limited, suggesting that China's crude oil market needs to be more open and fully competitive to attain the goal of integrating the domestic crude oil market with the international market. When the Chinese crude oil market was affected by an external shock, it should ask for a solution from the international crude oil market.

4.3. VEC-TARCH Model. Table 3 shows the estimated coefficients of the VEC-TARCH model. The values of $a_{11}$ and $b_{11}$ were 0.0746 and 1.0074 and deviate from zero at the significance level of 0.01 , suggesting that the conditional variance of the Chinese crude oil price was affected by both the stochastic term in the last period and the prior conditional variance. In other words, the Chinese crude oil price volatility was influenced by both the last period's external shock and the last period's forecast variance based on past information. Moreover, $a_{11}$ was much smaller than $b_{11}$, implying that the Chinese crude oil price volatility was mainly affected by its previous volatility transmission. The sum of $a_{11}$ and $b_{11}$ was 1.082, just outnumbering one, which indicated that the shocks to the volatility of the Chinese crude oil price would die out slowly. Similarly, the values of $a_{22}$ and $b_{22}$ were 0.0989 and 0.9927 and significant, indicating that the international
TABLE 3: Estimated coefficients of the VEC-TARCH model between $p_{-} 1$ and $p_{2}$. " “***", “**” and "*” denote the significance by $z$ statistic at the $1 \%, 5 \%$ and $10 \%$ level, respectively.

\begin{tabular}{lc}
\hline Coefficient & Value \\
\hline$c_{0}$ & $0.0100^{*}$ \\
$a_{11}$ & $0.0746^{* * *}$ \\
$a_{12}$ & $0.0464^{* * *}$ \\
$a_{22}$ & $0.0989^{* * *}$ \\
$d_{11}$ & $-0.1002^{* * *}$ \\
$d_{12}$ & $-0.0865^{* * *}$ \\
$d_{22}$ & $-0.1335^{* * *}$ \\
$b_{11}$ & $1.0074^{* * *}$ \\
$b_{12}$ & $1.0277^{* * *}$ \\
$b_{22}$ & $0.9927^{* * *}$ \\
\hline
\end{tabular}

crude oil price's conditional variance was affected by both the stochastic term in the last period and the prior conditional variance. The sum of $a_{22}$ and $b_{22}$ was very close to one, illustrating that the shocks to international crude oil price volatility would die out slowly as well. The values of $a_{12}$ and $b_{12}$ were 0.0464 and 1.0277 , respectively, implying that the two variables' joint volatility was affected by both the stochastic term's volatility in the last period and the prior conditional covariance. In addition, $a_{12}$ was far lower than $b_{12}$, demonstrating that the two variables' joint volatility was primarily affected by the prior joint volatility. The sum of $a_{12}$ and $b_{12}$ was also close to one, which demonstrated that the shocks to the two variables' joint volatility would disappear as well.

The volatility of both of the Chinese and international crude oil prices was primarily affected by the previous conditional variance forecast. In other words, their current volatility was mainly originated from previous volatility 
transmission, implying that both oil prices' volatility had the feature of endogeneity. That is to say, both China's and international crude oil markets had a respective endogenous volatility transmission mechanism. The last period's external shock did also affect their current volatility. In addition, the shocks to the volatility of both Chinese and international crude oil prices would disappear rather slowly, suggesting that the risk was increasing and the uncertainty of the crude oil market was growing both in China and in the world. Similarly, the current joint volatility of the Chinese and international crude oil prices was mainly affected by prior conditional covariance, implying that a stable relationship had been established between Chinese and international crude oil markets.

The elements of the dummy matrix $d_{t-1}$ reflect whether the volatility of the Chinese and international crude oil prices was symmetrical or not. The value of $d_{11}$ was -0.1002 and deviated from zero statistically significantly, manifesting that the volatility of the Chinese crude oil price was asymmetric and that positive news would exacerbate volatility more greatly than negative news. In China's crude oil market, pricing was under the central government's dominance. When there were rising signals in the international crude oil market, the current crude oil price in China tended to rise as well; when there were declining signals, the crude oil price in China tended to remain at the current level because the monopolistic petroleum enterprises in China may exert an influence on the government's decision. The value of $d_{22}$ was negative and showed that prior positive news impacted the international crude oil price more than negative news. In addition, the value of $d_{12}$ was negative and highly significant, which illustrates that when the product of the prior stochastic terms of the Chinese and international crude oil prices was positive, it affected the current joint volatility more than when it was negative. Because China's crude oil market was integrated with the international oil market, when the direction of the two variables' respective stochastic terms' external shock was consistent-that is, the product of the prior stochastic terms of Chinese and international crude oil prices was positive-the impact on the two variables' joint volatility was aggravated. On the other hand, when the direction of both was inconsistent, the impact on the two variables' current joint volatility counteracted.

\section{Conclusions}

This study first utilized the Granger causality model to test for a statistical causal relationship between the Chinese and international crude oil prices. Then, the impulse response function and variance decomposition were adopted to trace the effect of a one-time shock to one of the innovations on current and future values of the endogenous variables and the contribution of endogenous variables' structural shocks, respectively. Finally, a VEC-TARCH model was used to explore the two variables' volatility relationship and asymmetry. The main conclusions are as follows.

The Chinese and international crude oil prices were of reciprocal causation. The two crude oil markets have gradually linked with each other. However, because of the special crude oil pricing mechanism in China, an external shock's impact on the Chinese crude oil price was stronger and the Chinese crude oil price was sensitive to the change of the international crude oil price. Though the two crude oil markets affected each other, the buffering capacity of the international crude oil price to external shocks was stronger than that of China. As a result, the impact of shocks of the Chinese crude oil price on the international crude oil price was limited, whereas that of shocks of the international crude oil price on the Chinese crude oil price was larger. In addition, both the variance decomposition of Chinese and international crude oil price indicated that the former structural shocks' contribution was greater than the latter, further suggesting that the Chinese crude oil price was more sensitive to external shocks than the international crude oil price.

The volatility of the crude oil price both in China and in the world was affected by external shocks and their fluctuation transmission in the last period. But the corresponding coefficient of the previous conditional variance was far greater than that of the prior external shock, implying that the volatility of both Chinese and international crude oil prices was mainly transmitted by prior fluctuation and the external shocks' impact was limited. Furthermore, the joint volatility of the two variables was primarily influenced by their previous conditional covariance, reflecting that the Chinese crude oil market and international crude oil market were gradually integrated and that a stable relationship between them had been established. Finally, the volatility of the crude oil price both in China and in the world showed the feature of asymmetry and positive news' shocks on current volatility were larger than those of negative news. When the directions of the two variables' respective stochastic terms' external shocks were consistent, the impact on the two variables' joint volatility was aggravated, whereas when inconsistent, the impact on the two variables' current joint volatility was counteracted.

\section{Conflict of Interests}

The authors declare that there is no conflict of interests regarding the publication of this paper.

\section{Acknowledgments}

The authors gratefully acknowledge the financial support from the Key Project of National Social Science Funds in China under Grant no. 12\&ZD048, National Natural Science Foundation of China under Grants nos. 71503093 and 71273104, and the Fundamental Research Funds for the Central Universities under Grants nos. 2662014BQ044 and 2662015RW009.

\section{References}

[1] Z. Peng and W. Martin, "Oil price shocks and policy responses in the post-reform Chinese economy," Journal of Development Studies, vol. 31, no. 1, pp. 179-200, 1994. 
[2] I. Korhonen and S. Ledyaeva, "Trade linkages and macroeconomic effects of the price of oil," Energy Economics, vol. 32, no. 4, pp. 848-856, 2010.

[3] L. Du, H. Yanan, and C. Wei, "The relationship between oil price shocks and China's macro-economy: an empirical analysis," Energy Policy, vol. 38, no. 8, pp. 4142-4151, 2010.

[4] W. Q. Tang, L. B. Wu, and Z. X. Zhang, "Oil price shocks and their short- and long-term effects on the Chinese economy," Energy Economics, vol. 32, no. 1, pp. S3-S14, 2010.

[5] K. Y. Ju, D. Q. Zhou, P. Zhou, and J. M. Wu, "Macroeconomic effects of oil price shocks in China: an empirical study based on Hilbert-Huang transform and event study," Applied Energy, vol. 136, no. 12, pp. 1053-1066, 2014.

[6] J. R. Faria, A. V. Mollick, P. H. Albuquerque, and M. A. LeónLedesma, "The effect of oil price on China's exports," China Economic Review, vol. 20, no. 4, pp. 793-805, 2009.

[7] X. Wang and C. Zhang, "The impacts of global oil price shocks on China's fundamental industries," Energy Policy, vol. 68, pp. 394-402, 2014.

[8] J.-L. Jiao, H.-H. Gan, and Y.-M. Wei, "The impact of oil price shocks on Chinese industries," Energy Sources Part B: Economics, Planning, and Policy, vol. 7, no. 4, pp. 348-356, 2012.

[9] R.-G. Cong, Y.-M. Wei, J.-L. Jiao, and Y. Fan, "Relationships between oil price shocks and stock market: an empirical analysis from China," Energy Policy, vol. 36, no. 9, pp. 3544-3553, 2008.

[10] C. G. Zhang and X. Q. Chen, "The impact of global oil price shocks on China's bulk commodity markets and fundamental industries," Energy Policy, vol. 66, pp. 32-41, 2014.

[11] G. M. Caporale, F. M. Ali, and N. Spagnolo, "Oil price uncertainty and sectoral stock returns in China: a time-varying approach," China Economic Review, vol. 34, no. 7, pp. 311-321, 2015.

[12] B. Hearn and S. Y. Man, "An examination of price integration between stock market and international crude oil indices: evidence from China," Applied Economics Letters, vol. 18, no. 16, pp. 1595-1602, 2011.

[13] J. Wang, H. Pan, and F. Liu, "Forecasting crude oil price and stock price by jump stochastic time effective neural network model," Journal of Applied Mathematics, vol. 2012, Article ID 646475, 15 pages, 2012.

[14] D. C. Broadstock and G. Filis, "Oil price shocks and stock market returns: new evidence from the United States and China," Journal of International Financial Markets, Institutions and Money, vol. 33, no. 11, pp. 417-433, 2014.

[15] S.-F. Li, H.-M. Zhu, and K. M. Yu, "Oil prices and stock market in China: a sector analysis using panel cointegration with multiple breaks," Energy Economics, vol. 34, no. 6, pp. 1951-1958, 2012.

[16] C. C. Lin, C. R. Fang, and H. P. Cheng, "The impact of oil price shocks on the returns in China's stock market," Emerging Markets Finance and Trade, vol. 50, no. 5, pp. 193-205, 2014.

[17] C. C. Nguyen and M. I. Bhatti, "Copula model dependency between oil prices and stock markets: evidence from China and Vietnam," Journal of International Financial Markets, Institutions \& Money, vol. 22, no. 4, pp. 758-773, 2012.

[18] C. G. Zhang and X. Q. Chen, "The impact of global oil price shocks on China's stock returns: evidence from the ARJI(- $\left.\mathrm{h}_{t}\right)$ EGARCH model," Energy, vol. 36, no. 11, pp. 6627-6633, 2011.

[19] F. Lescaroux and V. Mignon, "Measuring the effects of oil prices on China's economy: a factor-augmented vector autoregressive approach," Pacific Economic Review, vol. 14, no. 3, pp. 410-425, 2009.
[20] B. L. Ou, X. Zhang, and S. Y. Wang, "How does China's macroeconomy response to the world crude oil price shock: a structural dynamic factor model approach," Computers \& Industrial Engineering, vol. 63, no. 3, pp. 634-640, 2012.

[21] J. Chai, J.-E. Guo, L. Meng, and S.-Y. Wang, "Exploring the core factors and its dynamic effects on oil price: an application on path analysis and BVAR-TVP model," Energy Policy, vol. 39, no. 12, pp. 8022-8036, 2011.

[22] A. Gallo, P. Mason, S. Shapiro, and M. Fabritius, "What is behind the increase in oil prices? Analyzing oil consumption and supply relationship with oil price," Energy, vol. 35, no. 10, pp. 4126-4141, 2010.

[23] J. Skeer and Y. Wang, "China on the move: oil price explosion?" Energy Policy, vol. 35, no. 1, pp. 678-691, 2007.

[24] A. Bénassy-Quéré, V. Mignon, and A. Penot, "China and the relationship between the oil price and the dollar," Energy Policy, vol. 35, no. 11, pp. 5795-5805, 2007.

[25] R. K. Kaufmann, "The role of market fundamentals and speculation in recent price changes for crude oil," Energy Policy, vol. 39, no. 1, pp. 105-115, 2011.

[26] H. Li and S. X. Lin, "Do emerging markets matter in the world oil pricing system? Evidence of imported crude by China and India," Energy Policy, vol. 39, no. 8, pp. 4624-4630, 2011.

[27] R. A. Ratti and J. L. Vespignani, "Liquidity and crude oil prices: China's influence over 1996-2011," Economic Modelling, vol. 33, no. 7, pp. 517-525, 2013.

[28] G. Wu and Y.-J. Zhang, "Does China factor matter? An econometric analysis of international crude oil prices," Energy Policy, vol. 72, no. 9, pp. 78-86, 2014.

[29] Y. P. Suo, Study of the market-oriented pricing mechanism for product oil in China [M.S. thesis], Beijing University of Posts and Telecommunications, 2013.

[30] Y. H. Zhang, Study of Chinese government functions about crude oil pricing mechanism reform [M.S. thesis], East China University of Political Science and Law, 2014.

[31] C. A. Sims, "Macroeconomics and reality," Econometrica, vol. 48, no. 1, pp. 1-48, 1980.

[32] C. W. J. Granger, "Investigating causal relations by econometric models and cross-spectral methods," Econometrica, vol. 37, no. 3, pp. 424-438, 1969.

[33] C. L. Chua, S. Suardi, and S. Tsiaplias, "An impulse-response function for a VAR with multivariate GARCH-in-mean that incorporates direct and indirect transmission of shocks," Economics Letters, vol. 117, no. 2, pp. 452-454, 2012.

[34] T. Bollerslev, R. F. Engle, and J. M. Wooldridge, "A capital asset pricing model with time-varying covariances," Journal of Political Economy, vol. 96, no. 1, pp. 116-131, 1988.

[35] T. Bollerslev, "Modelling the coherence in short-run nominal exchange rates: a multivariate generalized ARCH model," The Review of Economics and Statistics, vol. 72, no. 3, pp. 498-505, 1990.

[36] R. F. Engle and K. F. Kroner, "Multivariate simultaneous GARCH," Econometric Theory, vol. 11, no. 1, pp. 122-150, 1995.

[37] R. F. Engle, "Dynamic conditional correlation: a simple class of multivariate generalized autoregressive conditional heteroskedasticity models," Journal of Business \& Economic Statistics, vol. 20, no. 3, pp. 339-350, 2002.

[38] T. Bollerslev, "Generalized autoregressive conditional heteroskedasticity," Journal of Econometrics, vol. 31, no. 3, pp. 307327, 1986. 
[39] R. Rabemananjara and J. M. Zakoian, "Threshold arch models and asymmetries in volatility," Journal of Applied Econometrics, vol. 8, no. 1, pp. 31-49, 1993.

[40] K. C. Chen, S. L. Chen, and L. F. Wu, "Price causal relations between China and the world oil markets," Global Finance Journal, vol. 20, no. 2, pp. 107-118, 2009. 


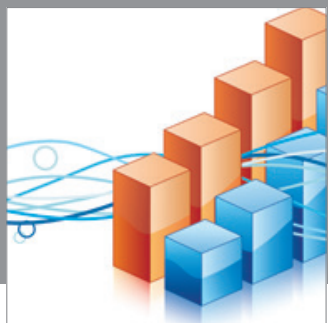

Advances in

Operations Research

mansans

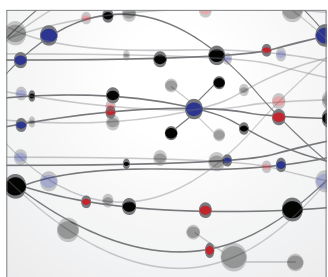

The Scientific World Journal
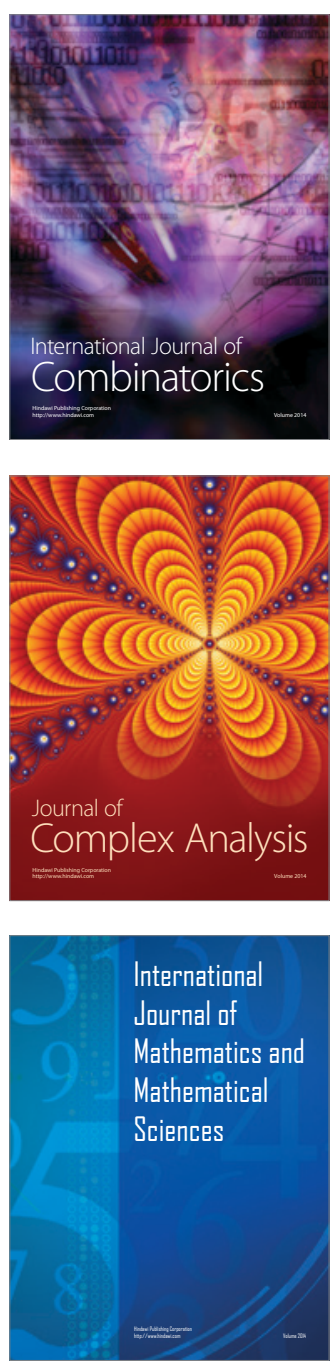
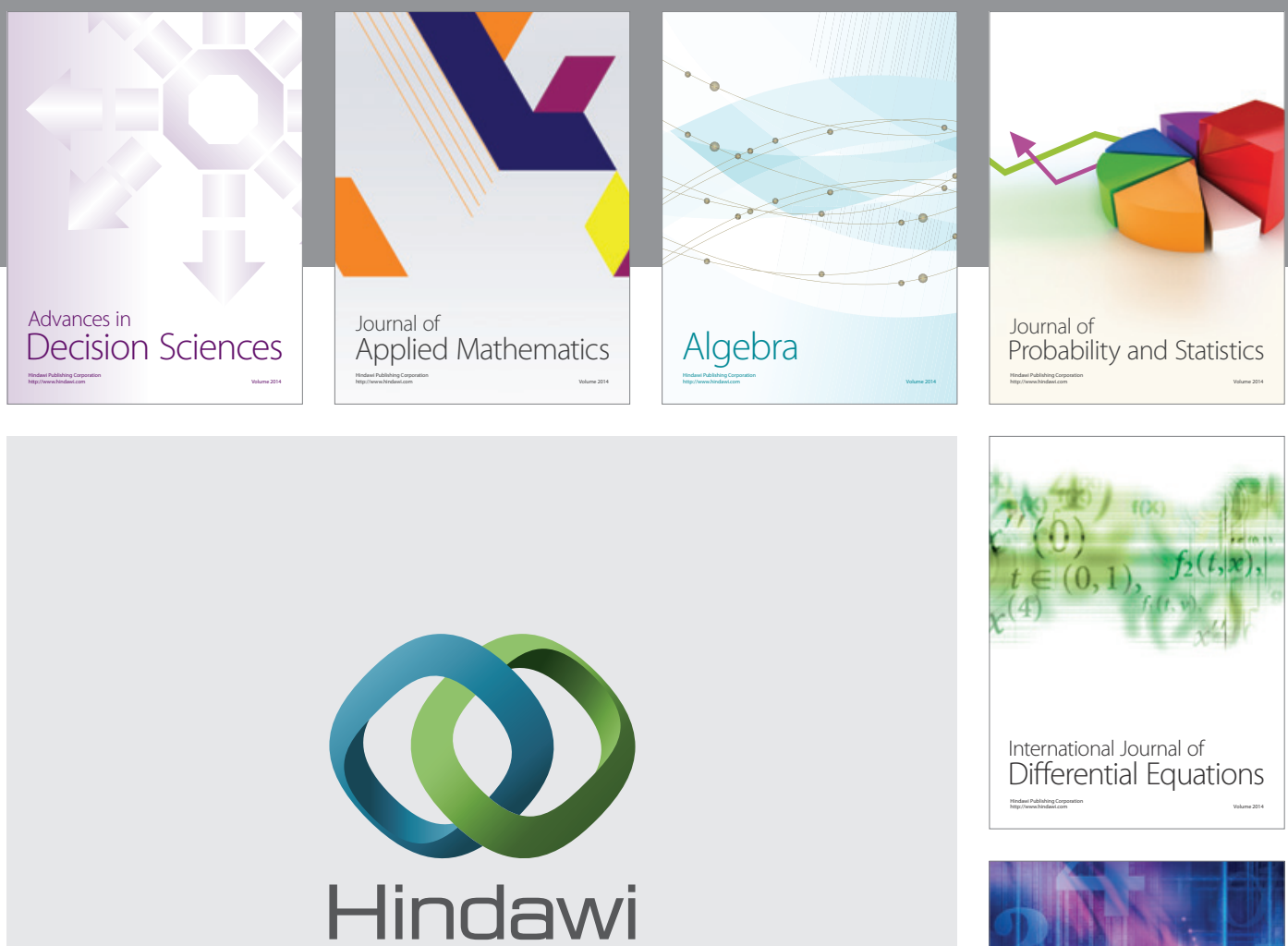

Submit your manuscripts at http://www.hindawi.com
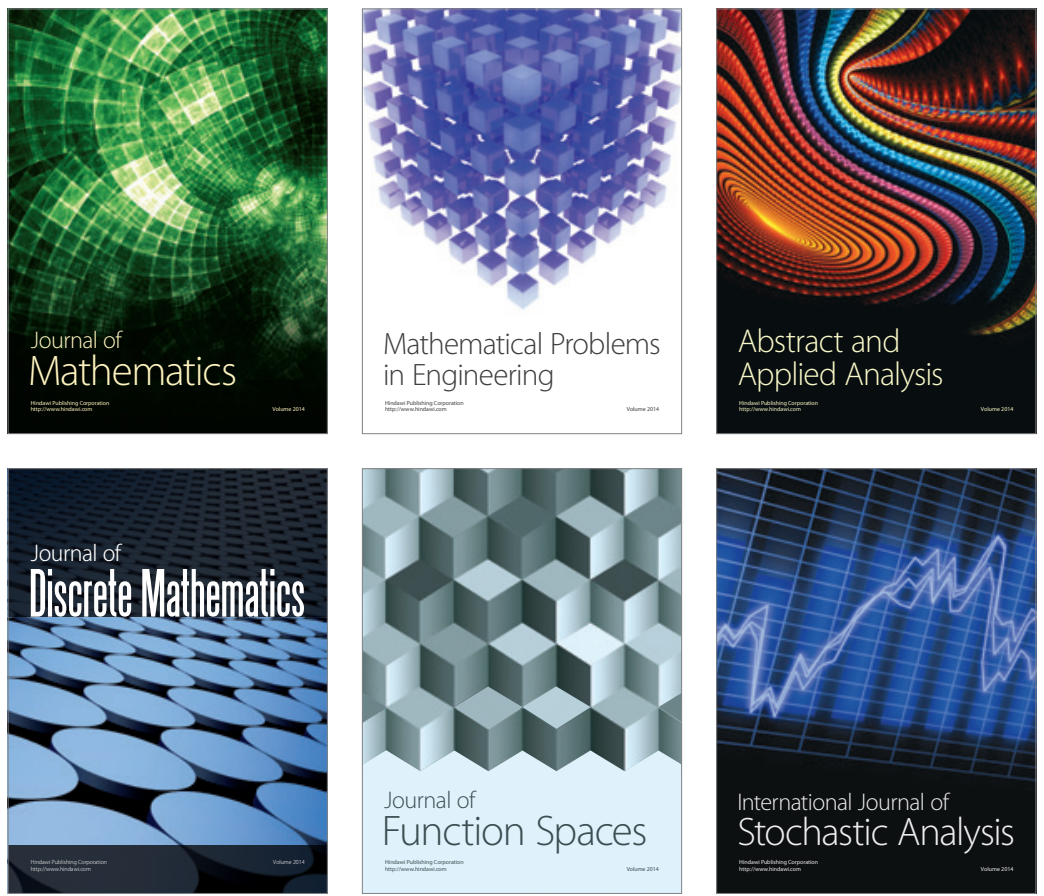

Journal of

Function Spaces

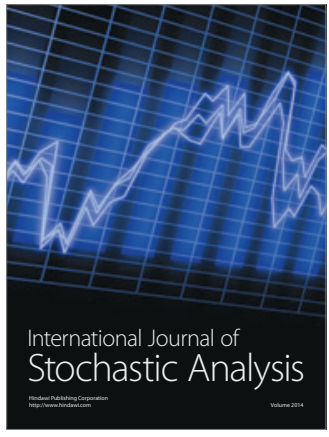

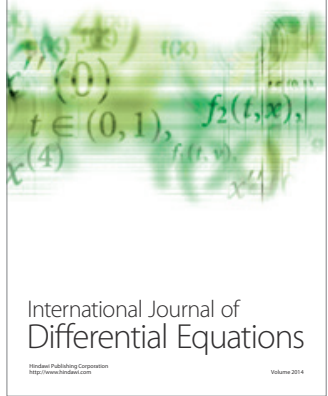
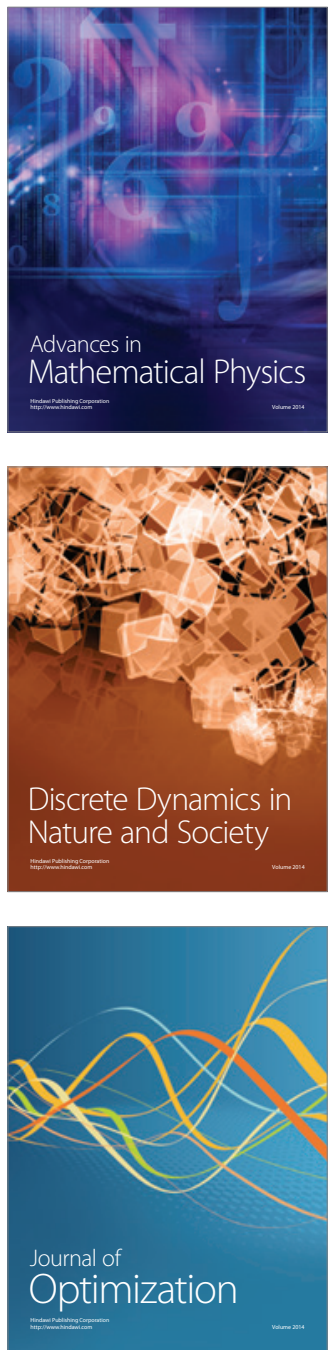